\section{Effects of Expiratory Positive Airway Pressure on Dynamic Hyperinflation During Exercise in Patients With COPD}

\section{To the Editor:}

I read the interesting study by Monteiro et al. ${ }^{1}$ However, I would like to point out the relevant findings by Cordoni et al. ${ }^{2}$ Monteiro et al reported 17 (37\%) patients with COPD and substantial dynamic hyperinflation $(\mathrm{DH})$ as defined by at least a $15 \%$ reduction from pre-exercise inspiratory capacity (IC). They concluded that the application of expiratory positive airway pressure (EPAP) reduced $\mathrm{DH}$, as shown by lower operational lung volumes after submaximal exercise in COPD patients who previously manifested exercise DH. ${ }^{1}$

Cordoni et al evaluated 30 patients with COPD. ${ }^{2}$ Nineteen $(63.30 \%)$ patients had significant reduction in IC and were classified in the $\mathrm{DH}$ group, and 11 showed no reduction in IC or even had an increase in IC and were therefore included in the no-DH group. $^{2}$

Interestingly, although the DH group had a greater pre-exercise IC, this group had an abrupt decline in the rest-exercise transition period. Statistically significant correlations among the variations in IC, tolerance limited, and dyspnea score at the end of test were found only in the $\mathrm{DH}$ group. ${ }^{2}$

Cordoni et al presented more detailed analysis of behavior of operating lung volumes in the $\mathrm{DH}$ group, which revealed different patterns on decline of IC throughout the test. Among the 19 patients with $\mathrm{DH}$ group, the decrease in IC in the restexercise transition showed that at the $2 \mathrm{~min}$ mark 7 patients had progressive reduction in IC (progressive DH), and 12 had a stable pattern of reduction in the IC (stable DH). The subgroup of the DH group with progressive reduction in IC had more pulmonary function test impairment at rest, lower exercise tolerance, possibly greater perception of dyspnea, and more perception of leg fatigue. $^{2}$

From a clinical standpoint, those with progressive DH would benefit the most from interventions that decrease muscle overload, such as the use of bronchodilators and EPAP. ${ }^{2}$ The valuable findings of Monteiro et $\mathrm{al}^{1}$ in pointing out the benefits of utilizing EPAP in patients with DH and decreased IC, should probably be reevaluated in view of the findings of Cordoni et al, ${ }^{2}$ and be applied to patients with documented progressive DH. Perhaps narrowing the application of EPAP to patients with COPD and progressive $\mathrm{DH}$, since Cordoni et al found that the $\mathrm{DH}$ group had more clinical and laboratory findings of impairment, would result in better utilization of resources and augmentation of treatment outcome.

Samer Alkhuja MD

Department of Medicine

The Commonwealth Medical College East Stroudsburg, Pennsylvania

The author has disclosed no conflicts of interest.

\section{REFERENCES}

1. Monteiro MB, Berton DC, Moreira MA, Menna-Barreto SS, Teixeira PJ. Effects of expiratory positive airway pressure on $\mathrm{dy}$ namic hyperinflation during exercise in patients with COPD. Respir Care 2012;57(9): 1405-1412.

2. Cordoni PK, Berton DC, Squassoni SD, Scuarcialupi ME, Neder JA, Fiss E. Dynamic hyperinflation during treadmill exercise testing in patients with moderate to severe COPD. J Bars Pneumol 2012;38(1): 13-23.

\section{The Authors Respond:}

We would like to thank Dr Alkhuja for his comments regarding our paper. ${ }^{1}$ The etiology of exercise intolerance in patients with COPD is considered to be multifactorial, with dynamic hyperinflation (DH) having been identified as a key component. Physiology-based strategies to reduce hyperinflation and improve exercise tolerance are important tools in the management of patients with COPD. Four main interventions that reduce hyperinflation during exercise have been identified: bronchodilators, supplemental oxygen, helium/oxygen inhalation, and exercise training reconditioning. ${ }^{2}$

We demonstrated in our study that the application of expiratory positive airway pressure reduces exercise-related DH. ${ }^{1}$ The kinetic behavior of DH seems to be more complex than previously thought, however, with some patients able to delay ${ }^{3}$ or even avoid ${ }^{4}$ its development during cycle ergometry.

Cordoni et $\mathrm{al}^{5}$ demonstrated DH patterns using ambulation, rather than cycling, in patients with moderate to severe COPD, show- ing that these patterns are not artifacts of cycling exercise. They further demonstrated that a pattern of progressively increasing operating lung volumes in DH patients has a greater impact on exercise tolerance than does a stable pattern. These differing patterns may explain why not all patients derive similar exercise tolerance benefits from DH-reduction strategies. ${ }^{6}$

We agree with Dr Alkhuja that patients with progressive DH would see the most benefit from interventions aimed at reducing DH. Although this issue was not directly investigated in our study, we believe that our patient population consisted mainly of patients with progressive DH. We limited our investigation to patients with previously demonstrated overt $\mathrm{DH}$, defined as an inspiratory capacity reduction of at least $15 \%$ from rest. As demonstrated in Figure 2 of Cordoni et al, patients with progressive DH show greater decrements in inspiratory capacity with exercise.

The criterion used to classify DH is also relevant. Recently, Louvaris et al studied COPD patients with and without HD. In order to make this classification, they adopted the criterion of an inspiratory capacity decrease of greater than $4.5 \%$ of the baseline value, or greater than $150 \mathrm{~mL} .^{7}$ Cordonie et al considered DH to constitute any drop in inspiratory capacity, compared with the baseline value. This discrepancy in definition undermines the comparability of the findings as well as the ability of this classification to identify patients who will benefit from $\mathrm{DH}$ treatments.

In patients with $\mathrm{DH}$, a pattern of progressive reduction in operative lung volumes has a greater impact on exercise tolerance than does a stable pattern. ${ }^{6}$ This reinforces the importance of constant monitoring of these variables during exercise, not just before and after activity.

Additional studies are needed to measure the impact of DH patterns on pharmacologic and nonpharmacologic interventions aimed at reducing DH and improving exercise tolerance in patients with COPD. As Dr Alkhuja points out, this would certainly result in better resource utilization and improved treatment outcomes.

Mariane Borba Monteiro DSc
Department of Physiotherapy
Centro Universitário Metodista
Instituto Porto Alegre
Porto Alegre, Brazil 
Danilo Cortozi Berton DSc

Post-Graduate Program in Sciences

(Pulmonology)

Federal University of Rio Grande do Sul

Porto Alegre, Brazil

Paulo José Zimermann Teixeira DSc

Health Science Institute

Feevale University

Novo Hamburgo, Brazil

The authors have disclosed no conflicts of interest.

\section{REFERENCES}

1. Monteiro MB, Berton DC, Moreira MA, Menna-Barreto SS, Teixeira PJ. Effects of expiratory positive airway pressure on dynamic hyperinflation during exercise in patients with COPD. Respir Care 2012; 57(9):1405-1412.

2. Casaburi R, Porszasz J. Reduction of hyperinflation by pharmacologic and other interventions. Proc Am Thorac Soc 2006; 3(2):185-189.

3. Vogiatzis I, Georgiadou O, Golemati S, Aliverti A, Kosmas E, Kastanakis E. Patterns of dynamic hyperinflation during exercise and recovery in patients with severe chronic obstructive pulmonary disease. Thorax 2005;60(9):723-729.

4. Aliverti A, Stevenson N, Dellacà RL, Lo Mauro A, Pedotti A, Calverley PM. Regional chest wall volumes during exercise in chronic obstructive pulmonary disease. Thorax 2004;59(3):210-216.

5. Cordoni PK, Berton DC, Squassoni SD, Scuarcialupi ME, Neder JA, Fiss E. Dynamic hyperinflation during treadmill exercise testing in patients with moderate to severe COPD. J Bras Pneumol 2012; 38(1):13-23.

6. Aliverti A, Rodger K, Dellacà RL, Stevenson N, Lo Mauro A, Pedotti A, Calverley PM. Effect of salbutamol on lung function and chest wall volumes at rest and during exercise in COPD.Thorax 2005;60(11): 916-924.

7. Louvaris Z, Zakynthinos S, Aliverti A, Habazetto H, Vasilopoulou M, Andrianopoulos, Wagner $\mathrm{H}$, et al. Heliox increases quadríceps muscle oxygen delivery during exercise in COPD patients with and without dynamic hyperinflation. J Appl Physiol 2012;113(7):1012-1023.

\section{Humidification During Noninvasive Ventilation in the Critically IIl}

\section{To the Editor:}

Although humidifiers have demonstrated beneficial therapeutic effects during nonin- vasive ventilation (NIV), there is still controversy over the selection of the best humidifier to improve patient-ventilator interaction and gas exchange. ${ }^{1}$ We read with interest the recently published study by Lellouche et $\mathrm{al},{ }^{2}$ who analyzed the shortterm effects of 2 types of humidifiers: heat and moisture exchanger (HME) and heated humidifier. The authors hypothesize that humidifiers may influence gas exchange and mechanical ventilation parameters. However, there are some important issues related to the methodology and interpretation of data that need to be discussed.

First, the study population was diverse (including both hypoxemic and hypercapnic respiratory failure). The different pathophysiological mechanisms of the 2 problems may influence the effects of humidifiers. ${ }^{1}$

Second, the results related to some measured ventilatory parameters need further discussion: tidal volume and minute volume ( $\dot{V}_{\text {E)}}$; HME internal dead space; HME internal resistance and performance; NIV air flow; and evaluation of $\mathrm{PCO}_{2}$ control and efficacy.

\section{Tidal Volume and Minute Volume}

In this study there was no difference in the expired tidal volume between the HME and the heated humidifier: median (IQR) $535 \mathrm{~mL}(456-638 \mathrm{~mL})$ versus $545 \mathrm{~mL}$ $(453-667 \mathrm{~mL}) .^{2}$ It is not clear in the methodology where the expired tidal volume was measured. Moreover, the paper did not discuss the potential effects of humidification devices on the in-line measurement of tidal volume, which theoretically may influence the volume delivered to the patient. On the other hand, $\dot{V}_{\mathrm{E}}$ was different with the HME and heated humidifier: median (IQR) $15 \mathrm{~L} /$ $\min (12-18 \mathrm{~L} / \mathrm{min})$ versus $12 \mathrm{~L} / \mathrm{min}(10-$ $16 \mathrm{~L} / \mathrm{min})$, respectively $(P<.001)$. High $\dot{\mathrm{V}} \mathrm{E}$, particularly in patients with hypercapnia and acidosis, could have a significant effect on the internal resistance of HMEs. ${ }^{3-5}$

\section{HME Internal Dead Space}

The average dead space in the Lellouche et al study was of $22-95 \mathrm{~mL}$ (mean $60 \mathrm{~mL}$ ). ${ }^{2}$ In an earlier study the same group measured the internal resistance of different HMEs and reported varied internal resistances. ${ }^{6}$ The results obtained in this study cannot be generalized to all HMEs, as there are several HMEs with different dead space. The authors selected in their recent study the lower resistance model, with a dead space above the mean reported in their previous study. ${ }^{7}$ The potential clinical implications of this were not discussed in the paper. ${ }^{2}$ Currently there are no studies that have evaluated the effect of a variable dead space and internal resistance of HMEs on patients during NIV.

\section{HME Internal Resistance and Performance}

Although the internal resistance of the HME is usually very low, it remains an important factor to consider when selecting humidifiers, particularly when higher air flow and $\dot{V}$ E are used. ${ }^{3,4}$ In some cases, suboptimal pressure support levels may be insufficient to overcome the humidifier's internal resistance and, hence, may lead indirectly to a slower decrease in $\mathrm{PaCO}_{2}$, as shown in the current study. ${ }^{2}$ Such effect will be of greater relevance in patients with higher degrees of expiratory air flow obstruction and acidosis. ${ }^{8}$ As the pulmonary function test values of the study population were not reported in this study, it is difficult to comment on this issue.

\section{Air Flow During NIV}

The performance of the HME was described in a previous bench study at air flow of $60 \mathrm{~L} / \mathrm{min}$, which is much lower than the air flow used during NIV. ${ }^{7}$ Therefore, it is important to evaluate the effect of air flow on the performance of HMEs in patients during NIV.

\section{Evaluation of $\mathrm{PCO}_{2}$ Control and Efficacy}

The authors attributed the slower control of $\mathrm{PaCO}_{2}$ levels to the increased HME dead space; however, this finding can be interpreted differently. In this study, breathing frequency was significantly higher in the HME model, compared to the heated humidifier model: 27 breaths/min (23-33 breaths/min) vs 24 breaths/min (20-30 breaths $/ \mathrm{min}), P<.001$. Breathing pattern and breathing frequency may influence gas exchange results, especially among hypercapnic patients. Elevated baseline $\mathrm{PaCO}_{2}$ may indicate a greater degree and severity of intrinsic PEEP. This aspect cannot be assessed in the current paper because we 